\title{
Bringing Environmental Justice to the Centre of Environmental Law Research: Developing a Collective Case Study Methodology
}

Jane Holder and Donald McGillivray

\section{Introduction}

The place of academia in the environmental justice movement is easy to locate. There are trails of work seeking to define, theorise and conceptualise environmental justice and environmental racism. ${ }^{1}$ Some of this work has sought to expand and extrapolate understandings of environmental justice by applying evidence of inequity and unfairness arising from local conditions - the proximate and confluent occurrence of pollutants and harms to health - to global patterns of energy production and consumption. ${ }^{2}$ Striking linkages have been identified between injustices being felt at these different levels, with modes of energy production (coal fired power stations for example) contributing markedly to respiratory diseases

1 D. Taylor, 'The Rise of the Environmental Justice Paradigm: Injustice Framing and the Social Construction of Environmental Discourses' (2000) 43 Am Behavioral Scientist, 508; A. Dobson, Justice and the Environment: Concepts of Environmental Sustainability and Theories of Distributive Justice (OUP, 1998); D. Schlosberg, 'Reconceiving Environmental Justice: Global Movements and Political Theories' (2004) 13 Environmental Politics 517; J. Agyeman, Sustainable Communities and the Challenge of Environmental Justice (NYUP, 2005).

2 J. Ebbesson, and P. Okowa (eds) (2009) Environmental Law and Justice in Context (CUP);

$\mathrm{S}$. Cable and T. Shriver, 'Production and Extrapolation of Meaning in the Environmental Justice Movement' (2016) 15(4) Sociological Spectrum 419. 
amongst those living close by, as well as to global temperature rise. ${ }^{3}$ Many academics have taken on responsibility for highlighting the experience of vastly different and serious forms of environmental injustices, which are specific to particular contexts. ${ }^{4}$ Others have gathered histories and geographies together in a search for a unified (albeit pluralist) theory or principle of environmental justice, ${ }^{5}$ whilst demonstrating an awareness of the danger of an overly stabilising or consensual approach to what is meant by environmental justice. ${ }^{6}$ Justice emerges as a causative and structural factor in legal relations, institutions and procedures, and the aspiration of justice calls for specific kinds of responses which recognise underlying factors and differing contexts.

Reviewing this body of work in relation to thinking about research methodologies, a fine line may be drawn between first, representing accurately the specifics of a subject of research and second, making claims about this subject falling within a much more generalised category of cases of environmental injustice. A concern is that labelling particular social and ecological circumstances or phenomena as an instance of environmental injustice, and thereby forming part of a larger and possibly

\footnotetext{
${ }^{3}$ B. Bryant and E. Hockman, 'A Brief Comparison of the Civil Rights Movement and the Environmental Justice Movement', in Naguib, D. and Brulle, R.J. (eds), Power, Justice and the Environment: A Critical Appraisal of the Environmental Justice Movement (MIT Press, 2005), p. 36.

${ }^{4}$ Naguib and Brulle, Power, Justice and the Environment; Ebbesson, and Okowa, Environmental Law and Justice in Context; G. Gill, Environmental Justice in India: the National Green Tribunal (Routledge, 2016).
}

${ }^{5}$ Schlosberg, 'Reconceiving Environmental Justice', n. 1.

${ }^{6}$ R. Holifield, 'Defining Environmental Justice and Environmental Racism', (2001) 22(1) Urban Geography, 78. 
unrelated set of such cases, may amount to little more than appropriating the language of a powerful and broadly successful movement.

We recognise the significance and difficulties involved in representing, presenting and labelling social and environmental subjects as cases of environmental injustice. But we argue that bringing issues of environmental justice to the centre of legal research ${ }^{7}$ by developing appropriate research methods can encourage a fidelity to context whilst recognising and retaining a sense of the meanings, history and significance of the broader environmental justice movement, and gaining theoretical and analytical strength from this as a result. We therefore move away from examining how academics have contributed to debates about environmental justice, addressing instead how academics can pursue environmental justice by developing or revising certain research strategies and methodologies. We consider the extent to which bringing environmental justice to the centre of environmental law research might be considered to be a discrete research methodology, in which the formulation of research questions, and the structure and design of research methods is shaped by the needs of local communities already engaged in protest, campaigning, direct action, or plan making.

Taking a historical approach, we recall that the alliance of academics and environmental justice activists in the United States in the 1960s and 1970s helped build the environmental justice movement. ${ }^{8}$ This approach is influenced strongly by the political and ideological ideas of the environmental justice movement which

\footnotetext{
7 This idea of 'centring' is borrowed from J. R. Feagin, 'Social Justice and Sociology: Agendas for the Twenty-First Century', in W. Carroll (ed) Critical Strategies for Research (Canadian Scholars Press, 2004) p. 35.

${ }^{8}$ S. Cable, et al (eds) 'Mission Impossible? Environmental Activists' Collaborations with Professional Environmentalism and with Academics', in Pellow, and Brulle, Power, Justice and the Environment, $\mathrm{n}$. 2 .
} 
began at grassroots level (churches, colleges, community groups) in the United States in the 1960 s in close alliance with the civil rights movement. ${ }^{9}$ At the core of the environmental justice movement was the identification and explanation of uneven distributions of harmful and undesirable land uses according to prevailing racist and segregationist policies, opinions and laws. We explore the idea that the correspondence between local activism and campaigning and academia can be mutually reinforcing. Although often operating on different timescales, both activists and academics can contribute knowledge, insights and a variety of perspectives into a legal inquiry which is contextual in the sense of being rooted in a particular locality and, importantly, also highly responsive to local needs. Under these circumstances legal research can carry broader significance in terms of recognising and identifying on a far larger scale patterns in the way in which inequalities, unfairness and harms are meted and experienced.

A key concern in arguing for the centrality of environmental justice in environmental law research is the place and priority given to knowledge generated by communities - referred to in this Chapter as 'everyday evidence'. This might take the form of data arising from citizen science projects (for example air and noise pollution monitoring), or witness statements which attest to the longevity and closeness of local people's connections with open green spaces. Bringing environmental justice to the centre of environmental law research necessarily involves questioning the limited weight

\footnotetext{
${ }^{9}$ R. D. Bullard, Dumping in Dixie: Race, Class and Environmental Quality (Westview, 2000); R. Bullard, Unequal Protection: Environmental Justice and Communities of Colour (Sierra Club Books, 1994); S. Foster, 'Justice from the Ground Up: Distributive Inequalities, Grassroots Resistance and the Transformative Politics of the Environmental Justice Movement' (1998) 86 California Law Review 775; R. Lazarus, 'Pursuing "Environmental Justice": The Distributional Effects of Environmental Protection' (1993) 87 Northwestern University Law Review, 787; R. Lazarus, 'Highways and Bi-Ways for Environmental Justice' (2000) 31 Cumberland Law Review 569.
} 
attributed to everyday evidence in a broad range of environmental decision making and emphasising in a critical manner its current relative insignificance in decision making. This approach to environmental law research is influenced strongly by feminist research strategies and methodologies, in particular recognising the significance of 'everyday' practices as a type of situated knowledge. ${ }^{10}$ For analytical purposes we draw these concerns apart, developing critical research stances which relate closely to environmental justice (see further, below ${ }^{* \star *}$ ).

Drawing on classic studies of environmental justice, ${ }^{11}$ as well as our smaller scale experience of using case studies to research environmental assessment ${ }^{12}$ and the protection of open green spaces, ${ }^{13}$ we suggest that collective case studies (also known as multisite or multiple case studies) offer an opportunity to map out and realise common concerns and losses and the similar experiences of legal hurdles and challenges on the part of geographically disparate local communities. The collective nature of these studies helps to build up a picture of environmental injustices across different, but related, cases and are capable of revealing broad discriminatory and unfair practices in environmental decision making which may form part of a pattern of experiencing discrimination and lack of influence and participation

\footnotetext{
${ }^{10} \mathrm{~S}$. Whatmore, 'Heterogeneous Geographies: Reimagining the Spaces of N/nature', in I. Cook, D. Crouch, S. Naylor and J. Ryan (eds) Cultural Turns/Geographical Turns: Perspectives on Cultural Geography (Prentice Hall, 2000).

${ }^{11}$ As detailed in Dumping in Dixie, Rev. Robert Bullard drew up five descriptive 'community case studies', from Southern American states, each selected on the basis of the demographic and economic profiles of the population as well as the socio-historic context in which each environmental dispute arose. The case studies were combined with household surveys and interviews with local community organisation leaders.

12 J. Holder, Environmental Assessment: The Regulation of Decision Making (OUP, 2004).

${ }^{13}$ D. McGillivray and J. Holder, D. McGillivray and J. Holder, 'Law, Locality and Environment: the Case of Town and Village Greens' (2007) 3(1) International Journal of Law in Context 1-17.
} 
in decision making extending beyond the specifics of a particular site, environmental conflict or legal dispute. In this respect, the development of collective case studies provides a method of research practice but may also contribute to the generation or development of theories of environmental justice, crossing the line between specificity/context of experience in a locality and generality/unity of theory.

In this Chapter we begin by elaborating on what an environmental justice perspective brings to environmental law research, before discussing how using collective case studies supports an environmental justice approach, and, finally, what critical research stances might be engaged in this process of centring environmental justice, in theoretical terms and, more practically, by outlining the nature of collaboration and partnership arrangements between academics and environmental campaign groups.

\section{What an environmental justice perspective brings to environmental law research}

A starting point to this concern with deliberately pursuing environmental justice by developing research strategies and methodologies is the important debate begun by Fisher, Lange and Scotford ${ }^{14}$ in their 2009 review of the state of environmental law research and scholarship, and which has been the subject of critique, including in the context of identifying the environmental content of legal education. ${ }^{15}$ Their main argument is that a lack of careful and critical scrutiny about methodological issues on

${ }^{14}$ E. Fisher, B. Lange, and E. Scotford, 'Maturity and Methodology: Starting a Debate about Environmental Law Scholarship' (2009) 21(2) Journal of Environmental Law 213.

$15 \mathrm{~J}$. Holder, 'Identifying the Points of Contact and Engagement between Environmental Education and Legal Education' (2013) 40(3) Journal of Law and Society 541. 
the part of environmental law academics has hampered the discipline's development or maturity. Their point is that the success and quality of environmental law scholarship is not (and should not be) directly dependent upon the success of environmental law as a body of law in achieving certain environmental outcomes or promoting certain values. Rather they point out that conflating these two issues has clouded thinking about environmental law scholarship and environmental law itself, and has meant that 'environmental law scholars have focussed too much on the state of the environment and the law and too little on what they are doing', ${ }^{16}$ with, they argue, deleterious effects on the quality of the resulting environmental law scholarship. This amounts to a serious refutation of the potential campaigning role of environmental law, and warns against pursuing environmental protection agendas through the development of environmental law scholarship. This argument has been taken up and countered by Pedersen who instead explained the subject's apparent incoherence as more a product of the diversity of subjective understandings, and sites, of risk. ${ }^{17}$ Very similar debates have taken place, famously, within sociology, ${ }^{18}$ and, more recently, geography. ${ }^{19}$

The concerns expressed by Fisher, Lange and Scotford attest to the legitimacy and scholarly standing of environmental law, less so the potential transformative value of the discipline in fostering environmental awareness, via teaching, or the active

\footnotetext{
${ }^{16}$ p. 217.

${ }^{17}$ O. Pedersen, 'The Modest Pragmatic Lessons for a Diverse and Incoherent Environmental Law' (2013) 33(1) Oxford Journal of Legal Studies 103.

18 Witness the debate about whether sociologists should be involved in improving society, as opposed to focusing, efficiently, on using statistical methods to discover knowledge about society, discussed by J. Feagin, 'Social Justice and Sociology: Agendas for the Twenty-First Century' (2001) 60(1) American Sociological Review, 1.

19 P. Routledge and K.D. Derickson, 'Situated Solidarities and the Practice of Scholar-Activism' (2015) Environment and Planning D: Society and Space, 391.
} 
participation of academics in groups resisting harmful environmental impacts and pollutants from development and industrial activity. This position has been tackled on the basis of empiricism: that the nature of the environmental concerns being addressed ('the state of the environment') can usefully and importantly shape research methods. For example, sensitivity to environmental conditions on the ground and a clear agenda for public participation in decision making have led academics researching environmental injustices and the significance of local environmental knowledge to advance participatory research methods. ${ }^{20}$ Connections have also been made clearly between the material reality of urban environmental contexts and the application of systems theory. ${ }^{21}$

These examples highlight that bringing together environmental law scholarship and inquiry about the state of the environment as a single intellectual, pedagogical and empirical endeavour has an important ethical dimension, the value of which has been recognised in varied ways and contexts by authors concerned with exactly what is at stake in cases of environmental loss and harm. ${ }^{22}$ For example Lazarus' detailed critique of US Supreme Court judgments led him to conclude that many

\footnotetext{
${ }^{20}$ Cable, S. et al, 'Mission Impossible? Environmental Activists' Collaborations with Professional Environmentalism and with Academics', n. 8; G. Ottinger, 'Community-based Science: A Strategy for Achieving Environmental Justice and Improving Environmental Knowledge', White Paper (Chemical Heritage Foundation, 2011); M. Minkler et al, 'Promoting Environmental Justice Through CommunityBased Participatory Research: The Role of Community and Partnership Capacity' (2008) 35(1) Health Education and Behaviour, 119.

${ }^{21}$ A. Philippopoulos-Mihalopoulos, Absent Environments: Theorising Environmental Law and the City (Routledge, 2007).

${ }^{22}$ A. Flournoy, 'In Search of an Environmental Ethic' (2003) Columbia J Envtl L 63; R. Lazarus, 'Restoring What's Environmental About Environmental Law in the Supreme Court' (2000) 47 UCLA L Rev 703; M. M'Gonigle and P. Ramsay 'Greening Environmental Law: From Sectoral Reform to Systematic Re-Formation', (2004) $14 \mathrm{~J}$ of Envtl L and Practice 333; E. Freyfogle, 'The Ethical Strands of Environmental Law' (1994) U III L Rev 819; D. Farber, 'Environmental Protection as a Learning Experience' (1994) 27(3) Loyola L Rev 791.
} 
judges perceive environmental law as an 'incidental factual context', ${ }^{23}$ ignoring the unique nature of the issues at the heart of environmental law disputes, namely the 'noneconomic, nonhuman character of the injuries'. ${ }^{24}$ To this list might also be added irreversibility, seriousness, uncertain and unforeseen consequences, and barely understood knock-on effects in natural systems. Tribe similarly refers to what is at stake - what may be lost - as the 'ultimate question', namely, whether we want future generations 'to live in, and enjoy, a plastic world', ${ }^{25}$ thereby losing the thread of continuity in time. For Lazarus and Tribe, this refocusing exercise on valuing the environment - the uniquely environmental quality of environmental law - actually contributes to the coherence of the subject, ${ }^{26}$ rather than, as Fisher, Lange and Scotford suggest, detracting from this and hence stalling the development of environmental law into 'maturity'.

The centrality and potentially transformative role of environmental ethics in legal research (as in legal education) makes a strong case for inquiry about the state of the environment. Developing an environmental justice perspective in environmental law research further sharpens the focus of this inquiry so that the main concern becomes the state of the environment as it is experienced, lived and protected by local people. Adopting this perspective is a deliberate attempt to bring strategies for carrying out environmental research within the category of critical research and, specifically, to adopt and further develop in the environmental sphere forms of

\footnotetext{
${ }^{23}$ R. Lazurus, 'Restoring What's Environmental About Environmental Law in the Supreme Court (2000) 47 UCLA L Rev 703, at 748.

${ }^{24}$ Lazarus, 'Restoring What's Environmental About Environmental Law in the Supreme Court', n. 23, at 748 .

${ }^{25}$ L. Tribe, L. 'Ways Not to Think About Plastic Trees' (1974) 83(7) Yale LJ 1315, 1327.

${ }^{26}$ Lazarus, 'Restoring What's Environmental About Environmental Law in the Supreme Court', n. 23, at 764 .
} 
community-based participatory research. The driving force of critical research strategies is the recognition that social science has a role to play in identifying, undoing, and transcending injustice. In thinking specifically about critical research in environmental law, this may be narrowed down to acknowledging that ecological degradation often stems from giving priority to short-term private profits over the 'health of the earth', ${ }^{27}$ and that this has profound and negative consequences for certain communities of people, particularly those who are most vulnerable to environmental harms, such as children ${ }^{28}$ and the elderly.

The critical edge of social science inquiry includes several important stances, each of which are significant for researching environmental law. The first is being oppositional - opposing the status quo arrangements that enforce and protect power. ${ }^{29}$ This stance leads to research which investigates and criticises structures and practices of domination which may be gendered or racialised and positions the researcher on the side of the oppressed or the side of critical social movements. A second stance of critical research is being radical, in the sense of getting to the root of matters in order to grasp the deep, systemic, bases of challenges and problems and identify the interconnections between issues at different levels and between social, economic and ecological spheres. ${ }^{30} \mathrm{~A}$ third stance in critical social science research is subversion, or the unsettling of accepted understandings, practices and identities in order to 'open a door to alternatives' ${ }^{31}$ Cumulatively, these positions, enacted through a diversity of methodologies and research techniques, lead to the

\footnotetext{
27 W. Carroll, Critical Strategies for Social Research (CSPI, 2004), p. 2.

${ }^{28}$ B. Hayward Children, Citizenship and the Environment (Earthscan, 2012).

${ }^{29}$ Carroll, Critical Strategies, n. 27, p. 3.

${ }^{30}$ Carroll, Critical Strategies, n. 27, p. 3.

${ }^{31}$ Carroll, Critical Strategies, n. 27, p. 3.
} 
'production of new knowledge that people rely on to guide their actions', ${ }^{32}$ with the overriding aim of bringing about social change.

When considering the specific role of legal research in advancing environmental justice, this overriding idea of the production of knowledge opens up the potential for legal research to become combined with the provision of legal advice to a group, community or individual, conferring knowledge in a targeted and applied manner. In this way giving advice then further shapes the direction of inquiry and setting of research questions. That environmental law research has utility for environmental justice purposes highlights the democratic and potentially empowering nature of critical research, as discussed further below in relation to the development of partnerships between academics, activists and campaigning organisations $\left({ }^{* * * *}\right)$.

Acknowledging and embracing the role of an environmental ethic within environmental law research helps to establish an important link to environmental justice because of the necessary shift of concern from individually felt harms and losses and a corresponding sense of individual responsibility or rights (an environmental ethic/environmental rights approach) to developing a sense of the impact felt by a community as a consequence of discriminatory decision making processes and practices and the substance of decisions (environmental justice concerns which may lead to collective political and legal responses). Such a shift can be understood in terms of the history of environmental law (as represented, for example, by Falk's 'cycles of urgency', ${ }^{33}$ whereby the prediction and identification of

\footnotetext{
${ }^{32}$ Carroll, Critical Strategies, n. 27, p. 4.

33 Falk, R. (2009) 'The Second Cycle of Environmental Urgency: An Environmental Perspective', in Ebbesson, and Okowa, Environmental Law and Justice in Context, n. 2.
} 
likely significant impacts (via environmental assessment and risk assessment) is no longer sufficient; instead, the differential, uneven - even targeted - nature of likely harms should be the key concern. This has great importance for environmental law methodologies because it suggests strongly that the abidingly collective factor of environmental justice should necessarily shape the methodological choices one is engaged in making as a researcher of environmental law in getting to the root of environmental injustices, whether in a distributional or procedural form, or a powerful combination of both of these. Properly understanding the collective or commonly felt loss of nature or experience of pollutants and developments requires research that scans beyond the individual case. We suggest that the development of collective case studies provides a means of creating analytical and theoretical linkages with several similar instances and cases of environmental injustice in a way which supports this overriding purpose of attesting to the occurrence of environmental harms and identifying the differential nature of their impacts.

\section{Understanding environmental justice via collective case studies}

Qualitative case study methodology can provide an insightful and intellectually meaningful way of studying complex phenomena in their real life context by drawing upon a variety of sources to build up a rounded, detailed and in-depth picture of the character and nature of the subject, over time and in a particular place. The importance of context differentiates case studies from other methods (quantitative or experimental study for example) in which the phenomenon under study is artificially 
taken outside of the context in which it exists and is observed in the abstract. ${ }^{34}$ Case studies have long been used in health science and education studies to inform clinical and professional practice, but, having fallen out of favour in social science research (due to concerns about the ability to extrapolate findings from case studies), the method was resuscitated, most notably by $\mathrm{Yin}^{35}$ and is now considered a serious option when doing social research. The utility and nature of this option lies not in an ability to represent a larger population of cases not studied or make generalisations, but, as Mitchell argues so persuasively, in establishing some essential features which characterise the projects studied and thereby allow analysis of how theories, principles or perspectives manifest themselves in a particular set of events. ${ }^{36}$ The crucial issue is not whether the findings can be generalized to a wider universe but how well the researcher generates a theory out of the findings or is capable of applying an existing theory in a way in which new theoretical insights are generated from in-depth analysis of a situation. When described as a research methodology case studies have been located at the 'intersection (and interaction) between theory and research methods and data'. ${ }^{37}$ Although alternative readings consider the use of case study in empirical research to be, not a methodology, but rather the result of a choice of what to study. ${ }^{38}$ Reflecting on the variety of case study types, a prototype approach makes sense, with an emphasis on establishing a set of core common features (as listed by van Wynsberghe and Khan in their

\footnotetext{
${ }^{34}$ T. Goddard, 'Collective Case Study' in A.J. Mills, G. Durepos and E. Wiebe, Encyclopedia of Case Study Research (Sage, 2010).

${ }^{35}$ R. Yin, 'The Case Study as a Serious Research Strategy' (1981) 3(1) Knowledge: Creation, Diffusion, Utilization, 97.

${ }^{36}$ C. Mitchell (1983) 'Case and Situation Analysis' 31(2) Sociological Review, 188.

37 G. Schoberg et al, 'The Case Study Approach in Social Research: Basic Methodological Issues', in J.R. Fegin and A. Orum (eds) A Case for the Case Study (Chapel Hill, 1991), p. 29.

${ }^{38}$ R. Stake, 'Qualitative Case Studies', in N. Denzin and Y. Lincoln (eds) The Sage Handbook of Qualitative Research (Sage, 2005) p. 438.
} 
redefining of the case study): ${ }^{39}$ intensive and in-depth focus on a specific unit of analysis; highly detailed, contextualised analysis - giving the reader a sense of 'being there'; reflecting natural settings in which behaviours, organisations or events are not controlled; providing a detailed description of a specific temporal and spatial boundary; drawing upon multiple data sources and 'extendability' (the last enriching the reader's experience rather than representing a broader category of similar cases).

Use of the case study method is commonplace in environmental research, ${ }^{40}$ allowing researchers to reflect and present sensitively the environmental setting of a case, as well as identifying the influences and impacts upon that setting. ${ }^{41}$ In addition to providing context, the location of setting of a case study therefore takes on additional significance as the site of environmental harm, threat or loss. Case study research can also help to reveal and understand the different disciplinary dimensions which make up a phenomenon under study. For example case study research of a particular conflict, campaign, or decision making process within a community, locality or organisation will be faceted and layered with political, economic, scientific and environmental aspects. This opportunity to draw upon for analytical purposes a multiplicity of viewpoints and sources within the context of a single setting supports an interdisciplinary approach to legal inquiry, now recognised as a vital element of carrying out research within environmental law. Finally, case study methodology has

\footnotetext{
${ }^{39}$ R. Wynsberghe and S. Khan, 'Redefining Case Study' (2007) 6(2) International Journal of Qualitative Methods 80.

${ }^{40}$ For example see Journal of Case Studies in the Environment (2017).

${ }^{41}$ S. Elworthy Farming for Drinking Water: A Study of a Regulatory Regime (Avebury, 1994); B. Lange, Implementing EU Pollution Control: Law and Integration (CUP); E. Witbooi, Fisheries and Sustainability: A Legal Analysis of EU and West African Agreements (Hart, 2011); M. Pieraccini, 'Rethinking Participation in Environmental Decision Making: Epistemologies of Marine Conservation in South East England' (2015) 27(1) Journal of Environmental Law 45.
} 
been associated positively with researching instances of collective action and common, sustainable, resource use in different regions, resource systems and from diverse disciplinary perspectives. The power of such case studies lies in making clear that that people tend not to overharvest shared resources, and in providing a foundation for evidence of successful collaborations by some resource users. Case study methodology is capable of identifying the conditions associated with the emergence and durability of collective action. ${ }^{42}$

Case study methodology has been catalogued into subcategories: explanatory, exploratory or descriptive, ${ }^{43}$ and, additionally, intrinsic (to study a unique situation in which one has an intrinsic interest), instrumental (to gain insight and understanding of a particular situation or phenomenon), and collective - also referred to as a multiple case study. ${ }^{44}$ This last category, collective case studies, involves clusters of cases being gathered together for analytical purposes, according to common elements and using similar methods of data collection but without the need for close physical or temporal connections. ${ }^{45}$ The main aim of using collective case studies is to shed light on the context and complex features of a particular phenomenon from a variety of perspectives. Examining several cases as part of the same research project can clearly encourage the similarities and differences between the chosen cases to be understood and explained. ${ }^{46}$ This may, however, mean that the researcher pays less attention to the specific context and more to the ways in which

\footnotetext{
42 A. Potee, M. Janssen and E. Ostrom, Working Together: Collective Action, the Commons and Multiple Methods in Practice (Princeton, 2010); see also L. Davies, 'Working Toward a Common Goal: Three Case Studies of Brownfield Development in Environmental Justice Communities', (1999) Stanford Environmental Law Journal, 285.

${ }^{43}$ R. Yin, Applications of Case Study Research (Sage, 2003), p. 57.

${ }^{44}$ R. E. Stake, Multiple Case Study Analysis (Guilford, 2006).

45 J. Gerring, Case Study Research: Principles and Practices (CUP, 2007).

${ }^{46}$ Yin, Applications of Case Study Research, n. 41, p. 47.
} 
the cases can be contrasted, leading to a concern about how to retain 'contextual insight'. ${ }^{47}$ For Bryman, this concern is balanced by the opportunities brought by comparative design within collective case studies to allow the distinguishing, or similar, characteristics of two or more cases to act as a springboard for theoretical reflections about contrasting or approximate findings. ${ }^{48}$

The use of collective case studies has a long history, with such studies being documented in nineteenth century European sociological research, and, counterintuitively, giving rise to the term monograph. ${ }^{49}$ Focusing on the contemporary relevance of this last category for research into environmental justice, there seems to be little deliberate use or development of collective case study methodology in environmental law. Below, we outline the way in which collective case studies can offer insights into the constituent and essential features and conditions of environmental injustices because of broad similarities which may be identified between the cases. These characteristics, when relating to environmental injustices, go beyond the similarities which form the basis of the decision to study them within a group of cases, precisely because of the presence of differing social and geographical settings; in other words collective case studies can help identify the common roots and experiences of environmental harms across time and space. It is for this reason that we have sought to develop the use of collective case studies to better understand and critique the law relating to the protection of open green spaces, as a matter of environmental justice.

\footnotetext{
${ }^{47}$ A. Bryman, Social Research Methods (OUP, 2008), p. 52.

${ }^{48}$ Bryman, Social Research Methods, n. 46, p. 52.

49 Notably, P. G. Frédéric Le Play, L'Organisation de la Famille (1871), as cited by J. Goddard,

'Collective Case Study', in Mills, Duprepos and Wiebe (2010), p. 2.
} 
Searching for environmental justice in open green spaces

In the course of conducting an on-going research project on the protection of open green spaces by local communities via the arcane legal mechanism of town or village green designation, ${ }^{50}$ we are using collective case study methodology, gathering together a cluster of cases representing each stage of the designation procedure. The collecting of case studies is an effort to understand the working of procedural justice in relation to the protection of open green spaces which are visited by and resonate with members of a locality through their continued and communal use. The division of the research project into stages emphasises the strongly procedural and sequential nature of the decision making process governed by law. The identification of cases in which problems have arisen for communities working their way through these procedural stages (often without legal assistance) is aimed at identifying and understanding the procedural justice dimension of such decision making. This procedural justice focus contributes to an assessment of the impact of discriminatory or unfair decision making and procedural practices for communities. The overall search for environmental justice in this research design is driven by recognising that a community-based concern with the protection of local space is at stake; the communal protection of land provides an essential link to the extensive and formative body of research on the alliance between environmental justice political activism and scholarship.

\footnotetext{
50 Searching for Environmental Justice in Town and Village Greens: Law and the Protection of Open Green Spaces.
} 
Our research project on searching for environmental justice in town or village greens is made up of four sets of case studies. The main indicators for selecting the component case studies are the presence of a communal response to a threat to communally used open green space and that a legal requirement has been triggered which, prima facie, raises questions of distributive and/or procedural justice. The collective case study approach lends itself to socio-legal inquiry based on the interpretation of a range of legal materials and social and legal events. The method allows a wide range of views and experiences of how people relate to and value local green spaces to be included in accounts of legal decision making processes in order to judge the extent to which such relational aspects are capable of informing outcomes. We became aware of the case studies through different means - via environmental law and social networks, ${ }^{51}$ contacts arising from public engagement events on town and village greens law, advice from legal professionals and, in two of the cases, from local and national media, such was their high legal and political profile. The case studies were not chosen on the basis of their typicality or representativeness of the pool of all applications for town and village green status but rather because they illustrate a range of land ownership and governance types and settings (urban, suburban, village, beach) and highlight certain procedural and distributive injustices. The set of case studies are heuristic rather than narrative in the sense that the detailed examination of events and texts using socio-legal perspectives and methods show up environmental injustices and encourage making theoretical and analytical linkages with other similar instances of environmental injustices. Whereas collective case studies are considered to provide the basis for comparative analysis, the aim of analysis in these cases is to find common ground in

${ }^{51}$ Particularly the Environmental Law Foundation and the Open Spaces Society. 
terms of the shared experience of environmental injustices in relation to the protection and loss of open green spaces.

The first collective case study (consisting of cases drawn from Mankley Fields (Gloucester), Chaucer Fields (Kent) and Coronation Gardens (Leicester)) concerns the process of applying to the local authority to register land as a green. This includes researching how local communities decide the grounds of their application based on a statutory test (land may be registered as a green if it can be established that a significant number of people in a locality have used the land 'as of right' for 'lawful sports and pastimes' for at least 20 years ${ }^{52}$ ). This test is subdivided according to several factual and temporal conditions which can create complexities in terms of establishing the boundary of the 'locality' as well as providing evidence of continued and 'sufficient' use of the land. The case studies, drawn from different areas of the country and focusing on very different types of open space (field, park, woods), have in common that this legal, technical and spatial test presents certain difficulties to local communities, exacerbated by the paucity of information and legal advice available to these communities. As a result, mistakes and errors are features of these initial applications to register land in this manner. The significance for environmental justice scholarship lies in assessing the extent to which this lack of expertise and advice contributed to adverse and substantive results for the communities involved and identifying whether those communities felt that they were treated fairly and with respect during this part of the process, according to theories of deliberative democracy (Dryzek, 2000) and procedural fairness (Tyler, 2000).

52 S. 15 Commons Act 2006. 
The second collective case study examines the working of the statutory tests for registering land as a green, focusing on recent case law which clarifies, but also restricts, the conditions governing this process. Key aspects here include procedural fairness issues about the inequality of legal resources held by the applicants and those seeking to oppose the registration of land in terms of being able to present their respective cases in legal fora such as public inquiries and council meetings, as raised by the (rejected) application to register Smithy Wood (South Yorkshire) and Somers Town (London Borough of Camden) residents' on-going application to register a town square as a green.

The third set of case studies provides examples of public and community-based involvement in decision making following the registration of land as a green, including resolving problems about the adequacy of resources to manage and conserve the land (analysed in the context of Kingsmead Park, Kent) as well as how disputes about the land, and its development, are handled, for example whether skateboarding falls within the category of 'lawful sports and pastimes' which define the use of a green and thereby necessitating the development of land (Steyning, West Sussex). A final set of case studies exemplifies the procedural justice consequences of the de-registration of a green, because of the apparently limited role for local communities at this stage of decision making (Curtis Fields, Dorset) and the legal complexities involved in the inter-relation of de-registration procedures with other regulatory regimes such as community asset transfer and rights of way (Newhaven 'West' Beach, East Sussex).

These collective case studies are being drawn up and analysed using a range of legal materials arising from the registration process: application forms and accompanying maps, public inquiry transcripts, witness statements and applicants' 
and opponents' legal submissions, inspectors' reports and decision letters, registration authorities' committee meeting minutes, judicial review applications, reported judgments and unreported court transcripts. Post-registration, relevant materials include: minutes from meetings held by local authorities, local residents' associations and wildlife trusts, management plans, and wildlife surveys. An essential part of the documentary analysis involved assessing the extent to which witness statements about how local people use and value green spaces and measure their potential loss are relied upon as evidence supporting inspectors' reports and subsequent decisions of the registration authority. Witness statements provide the backbone to inquiry proceedings: applicants, supporters and opponents are questioned and cross-examined on their statements. Witness statements form part of the 'bundle' of inquiry documents distributed by the applicants and opponents before the inquiry takes place; there may be well over a hundred statements submitted per inquiry. Although they have not been the subject of close research in environmental law, witness statements offer the opportunity to analyse texts written by local people with the aim of protecting land which may hold great meaning for them.

Apart from documentary analysis, we attended site visits, presentations, community meetings, case conferences and interviews, and public inquiries) and analysed transcripts from semi-structured interviews with applicants, campaigners, opponents, registration authorities, and legal professionals. The aim of conducting interviews is to clarify, further examine, and gain different perspectives on the role of public participation in decision making during the registration process and afterwards. In interviews we focus on analysing the significance of community-based evidence set out in witness statements and other legal documents, following initial textual analysis 
identifying and tracking such evidence through to decision letters and reports.

Finally, working from an environmental justice perspective, the process of analysing the data involves the participants - those applying for land to be registered as a town or village green - reviewing the case study interpretations and contributing new and/or additional perspectives on the issues under study.

\section{Elaborating critical research stances for environmental justice}

In the previous description and discussion of our research project we advance the use of collective case studies as a critical research strategy aimed at underscoring and understanding environmental injustices. The collective of cases provides a structure for research by gathering case material around a particular juncture in the legal process of registering land as a green to protect its long term use by a local community. The aim is then for this case material to be analysed according to a triumvirate of critical stances which map onto dimensions of justice procedural/distributive, spatial, and relational. These are elaborations, according to environmental justice, of the broad stances (opposition, radicalism and subversion) developed within critical social research, outlined above $\left({ }^{* * *}\right)$. Although developed specifically in the context of our research project on access to and protection of local land and its use, drawing upon Sen's 'realisation-focussed'53 idea of justice, this set of critical perspectives or stances may have more general applicability in environmental law research which is governed or shaped by a broad concern with advancing environmental justice through the identification and exposure of the instances and conditions of injustice. In Sen's evidence-based conception of justice,

${ }^{53}$ A. Sen, The Idea of Justice (Allen Law, 2009). 
the context in which injustice takes place is vital and the alleviation of injustices may be done outside institutional structures and architectures and prior to the creation of perfect models of justice. ${ }^{54}$ Working within this approach, Sen seeks to identify cases of injustice in terms of detailing the lives people live and the injustices they have suffered, in marked contrast to Rawls' more abstract, 'arrangement-focussed', ${ }^{55}$ view of justice which is drawn up according to what would be perfectly 'just' institutions.

\section{(i) Everyday evidence (distributional and procedural justice)}

This first elaborated stance for bringing environmental justice to the centre of critical social research arises from important questions about the process of producing knowledge, the nature of that knowledge and the weight that is attributed to 'everyday' knowledge in decision making processes. The role of 'citizen science' knowledge production by, and for, non-scientists - is a highly significant example of everyday evidence. A key example is 'bucket' monitoring (inexpensive, easy-tooperate, sampling devices) used to gather data on pollution events and air and water quality. Ottinger ${ }^{56}$ describes the great impact of one case in which residents captured evidence of air pollution caused by a chemical plant at times when air quality was particularly poor for instance immediately after releases from the works. This evidence compared markedly with state regulators' routine monitoring strategies which aimed at producing data on average concentrations of the toxic chemicals over long periods of time in order to compare with quality standards. Communitybased knowledge on the short term, spikes, of pollution challenged the salience of

\footnotetext{
${ }^{54}$ Sen, The Idea of Justice, p. 10.

${ }_{55}$ Sen, The Idea of Justice, p. 20.

${ }^{56}$ G. Ottinger, 'Buckets of Resistance: Standards and Effectiveness of Citizen Science' (2010) 35(2) Science, Technology and Human Values, 244.
} 
the current modes of air quality assessment whilst also highlighting the need for research into the effects of exposure to repeated peak toxics concentrations. The suggestion is that citizens' local knowledge has the capacity to improve environmental science and policy making by adding to and improving quantitative models and risk assessments. ${ }^{57}$ However, set against a few victories (prosecutions and enforcement actions), the theoretical potential of citizen science - even 'extreme citizen science ${ }^{58}$ - to transform decision making has arguably not been realised fully.

This stance opens up for critical analysis under what circumstances citizen science can produce results in terms of shaping policies and practice. For example, the significance of activists' socio-economic status relative to scientists and other experts and the substance of citizens' contributions have been examined, with social and economic disparities found to have profound consequences for the extent to which competing knowledge bases are accepted by decision makers and regulators. ${ }^{59}$ The responsiveness of decision makers and regulators to the claims of local residents is therefore varied and complex, and has a bearing upon ideas of both distributive injustice (the practice of uneven and discriminatory distribution of environmental pollutants and natural resources) and procedural injustice (the occurrence of legal hurdles and challenges which prevent individuals and groups from accessing legal advice and the courts and being treated fairly and with dignity in legal and political forums).

\footnotetext{
57 Ottinger, 'Buckets of Resistance', n. 55, 245.

58 'Extreme Citizen Science is a situated, bottom-up practice that takes into account local needs, practices and culture and works with broad networks of people to design and build new devices and knowledge creation processes that can transform the world' . https://www.ucl.ac.uk/excites

${ }^{59}$ A. Irwin, Citizen Science: A Study of Peoples, Expertise and Sustainable Development (Routledge, 1995).
} 


\section{(ii) Local/global interactions (spatial justice)}

This second elaborated critical stance is also vitally alert to local context, as a site of injustice, but additionally as a site of local political and environmental activism which connects, via networks, with global politics. Such processes of connecting and communicating help the development of protective strategies having very broad influence in favour of spatial justice (in recognition of the frequently unjust dynamics which arise from the organisation of space $\left.{ }^{60}\right)$. Sassens develops this idea of the significance on a global scale of the multiplicity and reverberation of local claimmaking and action: once local actions are recognised as recurring again and again in different sites, they gain global political significance. ${ }^{61}$ The significant consequence of this form of network based upon greater participation by local organisations, is the creation of trans-boundary public spheres, indicative of distributive forms of power arising from new digital formations and architectures and with women playing an increasingly active role in the articulation of such cross-border spaces. ${ }^{62}$ It has, of course, always been the case that local struggles and campaigns have attracted attention on a broader, even global, scale, but Sassens tracks the recent shaping and acceleration of this process through advances in information technology which have brought about this recognition with far greater magnitude, scope and simultaneity than previously. Although for Sassens 'cities are foremost'63 in this new geography of linked sub-national spaces transcending nation states (because of the

\footnotetext{
60 D. Harvey, Justice, Nature and the Geography of Difference (Wiley, 1996); E. Soja, Seeking Spatial Justice (University of Minnesota, 2010).

61 S. Sassens, 'Local Actors in Global Politics' (2004) 52(4) Current Sociology.

62 S. Sassens, 'Electronic Markets and Activist Networks: the Weight of Social Logics in Digital Formations', in R. Latham and S. Sassens (eds) Digital Formations: IT and New Architectures in the Global Realm (Princeton, 2005) p. 54.

63 Sassens, 'Local Actors in Global Politics', p. 3.
} 
way city inhabitants are capable of enacting 'some version of the global in the microspaces of daily life'64 via political and civic cultures), in researching the protection of local and open green spaces we find the same dynamic, but rooted in rural and suburban spaces. The environmental injustices arising from the modern replaying of ancient inequalities and absentee autocracy on the Isle of Eigg, for example, attracted wide world attention and support of indigenous rights activists. ${ }^{65}$

\section{(iii) Relation/situation and feminist approaches (relational justice)}

An important question arises about the extent to which spatial transcendence, explored by Sassens, has the effect of loosening, even unmooring, a sense of community identity from traditional sources such as the nation or village, ${ }^{66}$ and whether this has an adverse effect on conceptions of the local as a site of spatial justice. In researching the protection of local open green spaces we have found the prevalence and strength of a sense of identity or relational ethic, recognised and expressed by communities, especially in response to perceived threats to land which is communally used. This has led us to develop a third critical stance of advancing a relational approach to environmental justice, founded in feminist and eco-feminist theories of the ethics of care. ${ }^{67}$ This stance retains a strongly local focus (as with everyday evidence/citizen science) but shifts the focus from exposure to environmental harms (pollutants, waste) to instead recognising the great significance

\footnotetext{
64 Sassens, 'Local Actors in Global Politics', p. 3.

65 A. Mclntosh, Soil and Soul (Aurum, 2001).

${ }^{66}$ Sassens, 'Local Actors in Global Politics', p. 8.

67 H. Petersen, 'Gender and Environmental Law and Justice: Thoughts on Sustainable Development' in Ebbesson and Okowa (eds) Environmental Law and Justice in Context, drawing upon C. Gilligan, In a Different Voice: Psychological Theory and Women's Development (Harvard University Press, 1982).
} 
of certain places for local people and arguing that this be recognised in legal processes in a more meaningful way than is currently the case.

Our research on greens establishes that the limited nature of the statutory test for registering land as a town or village green, with its historic regard for 'lawful sports and pastimes', means that the legal process fails to capture both the full range and depth of meaning which use of local environments evokes and a true sense of what will be lost by the development of potential town or village green sites. A more relational approach to justice issues at the local level has been developed by critical geographers. Sarah Whatmore, for example, maps out the 'heterogenous geographies of life' in which an enlarged community of nature is no longer 'other' but is very much bound up in the shaping of 'the business of [our] everyday living'. ${ }^{68}$ She is interested in recognising 'relational configurations - living fabrics, spun between humans and nature, in place of the abstract spaces of social life'. ${ }^{69}$ The effect is to identify connections between 'everyday struggles' over local areas of land and largescale environmental degradation, and concerns about human health and well-being, and for the significance of these connections to be recognised in legal processes as a matter of environmental justice and making a positive contribution to the social construction of what Cooper terms 'everyday utopias'. ${ }^{70}$ The application of these theories to decision making about local green spaces highlights the relevance of a broad range of materials and ideas from different disciplines, acknowledging that issues of justice arising from land use and development cut across disciplinary

\footnotetext{
${ }^{68}$ S. Whatmore, 'Heterogeneous Geographies: Reimagining the Spaces of N/nature', in I. Cook, D. Crouch, S. Naylor and J. Ryan (eds), Cultural Turns/Geographical Turns: Perspectives on Cultural Geography (Prentice Hall, 2000), p. 297.

${ }^{69}$ Whatmore, 'Heterogeneous Geographies', n. 68, p. 297.

${ }^{70}$ Cooper, Everyday Utopias: The Conceptual Life of Promising Places (Duke, 2013).
} 
borders. A more material point is that local open spaces provide a vital means of connecting biodiversity, social diversity, and quality of life. People using local land on an everyday basis recognise these connections and find value in them and the relationships that develop as a result.

\section{Activism and communities of practice in law and academia}

Analysing the sets of collective case studies on the registration of land as greens according to these critical stances, we have found that the high level of legal activity in this niche but highly significant area of law has led to the development of formal and informal networks which allow participants (residents groups, protesters, applicants) to share their experiences of the legal system at certain junctures applying for registration of land, drawing up maps and plans, applying for judicial review, raising funds to pay for legal expertise ${ }^{71}$ and presenting cases at public inquiries - and that this creates opportunities for formal and informal learning about the law and legal practice. In this way, legal doctrine and legal authorities, as expressed in town and village green case law and particularly that generated by the highest courts, forms an important element of inter-group communication, informing communities' strategies for protecting green spaces. In this legal dynamic, case law exercises a 'structuring selective pull' 72 on decisions taking place locally, in the 'legal periphery ${ }^{173}$ about whether or not to apply for the registration of an area of land as a town or village green. Far from being an abstraction, in this area case law provides the context and points of influence for a range of decision making on the ground.

\footnotetext{
${ }^{71}$ See, for example, Crowd Justice https://www.crowdjustice.co.uk/case/beloved-mankley-field/

${ }^{72} \mathrm{~K}$. Ziegert, K. 'Systems Theory and Qualitative Socio-Legal Research', in R. Banakar and M.

Travers (eds) Theory and Method in Socio-Legal Research (Hart, 2005), p. 63.

73 Ziegert, Systems Theory', n. 70, p. 63.
} 
This is seen in several of the case studies in which social and legal elements constellate around a reported case. ${ }^{74}$

The influence and power of this concentration of legal and technical knowledge on decision making by local people, lawyers, inspectors and registrars is key to understanding a rounder version of socio-legal processes involved in protecting local green spaces. In analysing and presenting the case studies we seek to identify the points at which reported legal cases and case commentaries have had a bearing upon other social and legal decision making processes, refracting the content of case law to local circumstances. In such cases, it is possible that using collective case studies as a means of recognising what makes a successful or unsuccessful legal strategy and legal argument on a particular issue may help to create links between campaign groups where these had not been previously identified. In this way, communities of practice can grow up, providing a space for informal interactions between groups who share a concern or passion for something they do, ${ }^{75}$ and offering opportunities for the exchange of information and legal advice and social learning in marked contrast to hierarchical learning processes. ${ }^{76}$

An example of the potential of alliances growing up between researchers and local groups and activists is the development of a network of university clinics, working in partnership with the Environmental Law Foundation, a longstanding and well respected access to environmental justice charity which operates a referral system putting local groups in touch with environmental lawyers, and other experts, under

\footnotetext{
${ }^{74}$ For example, Mankley Fields judicial review of the local authority's decision not to allow applicants seeking to register land as a village green to correct their application.

${ }^{75}$ E. Wenger, Communities of Practice: Learning, Meaning and Identity (CUP, 1998), p. 4.

${ }^{76}$ As explored in the context of ESD (Education for Sustainable Development) networks, see Holder, 'Identifying the Points of Contact and Engagement between Environmental Education and Legal Education', n. 15, 541.
} 
taking pro bono work. ${ }^{77}$ Now involving students in the work of the ELF network of advice giving, this pattern of clinical and environmental education is reminiscent of M'Gonigle and Starke's description of law students, academics and activists being actively involved in developing commons-based forms of ownership and more facilitative laws for community-based investment. ${ }^{78}$ Such collaborations engender the university acting as a vehicle for social change through working with local communities, giving advice and advocacy, as part of 'responsible citizenship'. ${ }^{79}$ Other accounts of student and academic collaboration with members of local environmental justice groups point to how this offers opportunities for increased access to resources which might otherwise be denied to these groups. The idealism of this view is balanced by research which also indicates a lack of further success in terms of expanding more generally the environmental justice movements' social capital to amplify political pressure for significant structural economic and political changes. Interestingly, collaboration is most successful in the case of students' (as opposed to academic researchers') involvement with such groups, a product of students' deference to activists' local knowledge and lived experiences. ${ }^{80}$

\section{Conclusions}

\footnotetext{
77 For a comprehensive view of the role of universities in access to justice, see O. Drummond and G. McKeever, Access to Justice through University Law Clinics (University of Ulster, 2016).

${ }^{78}$ M. M'Gonigle and J. Starke, Planet U: Sustaining the World, Reinventing the University (Polis, 2006).

79 M'Gonigle and Starke, Planet U, p. 126.

80 Cable, S. et al (eds) (2005), 'Mission Impossible? Environmental Activists' Collaborations with Professional Environmentalism and with Academics', in D.N. Pellow, and R. J. Brulle (eds), Power, Justice and the Environment. A Critical Appraisal of the Environmental Justice Movement (MIT Press), p. 73.
} 
Drawing on our experience of structuring a research project based on collective case studies, and developing a critical framework for their analysis, we have offered some explanations for using this research design in environmental law research, rooted in a purposive approach of bringing environmental justice to the centre of research in environmental law. We have discussed the extent to which developing case study methodology can open up routes into key aspects of environmental research, allowing for a close analysis of the site in which a subject is embedded, and offering the opportunity to trace influences and impacts on this over time and space, as well as identifying a variety of disciplinary viewpoints which play upon that subject and determine its parameters, content and inter-relationships. The case study account can be detailed and in-depth, providing for theoretical insights and connections to be made between law, theory and practice. But, using a single case study is inevitably restricted, picturing a 'slice of life'. For this reason we have begun to develop a structure for research which is made up of several case studies collected around a particular stage in a procedural sequence, aimed at providing a way of differentiating and comparing situations and subjects, but, most importantly, gaining a sense of commonalities in the lived experience of injustice. The use of collective case studies to search for and understand the breadth, precedents, and communal responses to environmental harms - threatened, perceived or realised - hopefully brings environmental law research closer to the methodological needs and practical ambitions of the environmental justice movement, even though broader questions remain about the more tentative role of critical research in creating conditions for social change and environmental justice. 